\title{
Experiential Retailing Leveraged by Data Analytics
}

Urshita Ghosh Dastidar, Symbiosis Centre For Management and HRD, Symbiosis International University (Deemed), India Suhas Suresh Ambekar, Symbiosis Centre For Management and HRD, Symbiosis International University (Deemed), India Manoj Hudnurkar, Symbiosis Centre For Management and HRD, Symbiosis International University (Deemed), India Abhay D. Lidbe, Alabama Transportation Institute, University of Alabama, USA

(iD) https://orcid.org/0000-0001-7791-129X

\begin{abstract}
The purpose of the study is to establish how in retail industry consumer data can be leveraged and analysed to provide customers an enhance shopping experience. Popular machine learning algorithms related to text mining aids in parsing the natural language and helps to understand the brand image and what the brand currently is lacking. In the last decade, although ecommerce brought a revolution in retail industry, shopping trends show that consumers spend more in offline store than online. The rise of omni-channel retailing and data-driven decision-making are shifting retailer focus to providing enhanced in-store customer experiences. Retailers are trying to find ways to stand out in the highly competitive environment. The solution to this problem is providing retailtainment. This study helps to understand how the available customer data is to be analysed to create unique experiences and enable experience-based stores. The results of this study will help a retail company understand how omnichannel play an important role creating customer engagement strategies.
\end{abstract}

\section{KEYWORDS}

Customer Experience, Data Analytics, Omnichannel, Retailtainment, Sentiment Analysis

\section{INTRODUCTION}

Retail industry is being challenged by rapid digital transformation. In this sector, with the passage of time, consumer behavior also keeps changing. So, the retailers need to continuously grow and evolve and improve their business model, in tune with environmental changes (Begley, Fox, Lunawat, and MacKenzie, 2018). This offers them the chance to magnify customer engagement and upgrade the comprehensive shopping experience. Digital transformation is one such critical disruptor that has had a profound impact on shoppers and retailers. Advent of new technologies, increase in smartphone ownership, and Internet penetration has morphed shoppers' behavior and thus has been a key contributor to this change (Blazquez, 2014; Knowles, 2016). Tal Zvi Nathanel, CEO, Showfields, said 
that, "Today products are not bought, consumers buy stories and buy missions. Consumers actually define themselves by the products that they buy today."

Consumers' buying opportunities have expanded through an increased accessibility to products and services online with ease and convenience (Adityan, Harikrishnan, Anand, and Saju, 2017). Global e-commerce increase as a percentage of total retail sales is to be from 6.5 percent to 9.3 percent between 2012 and 2016 (Devitt, 2013). Some of the biggest retail organizations have declared financial insolvency since 2017, and this pattern is probably going to continue if no steps are taken to adapt in this volatile industry. On the other hand, global market analysis shows that 83 percent of purchased goods across the globe will take place in a brick and mortar shop by the year 2022. The store concept is making a return with the millennials and generation Z. Millennials constitute almost 20 percent of the global population, with large purchasing power (Euromonitor International, 2015).

Advent of online shopping has reduced the footfall of the brick and mortar stores. It has thus become important to explore the e-commerce channels and launch own shopping websites. There are more and more "hybrid" retailers who are selling their products through both online marketplace and traditional stores (Pozzi, 2013). There are multiple challenges in retail sector. We have seen the world getting impacted by the outbreak of COVID-19. Retailers today must confront bigger, tougher challenges due to that. Retail companies across the globe have closed their shutters temporarily, incurring huge revenue losses. They are also required to handle the unforeseen inventory and liquidity problems. Retailers find themselves competing with two sides. There are fast niche category retail stores on one side and huge digital platforms for shopping on the other. To thrive in the coming decade, retailers need to redesign and adapt the stores for digital era.

Online shopping also brings features like product recommendation, reviews, and large variety of products at one click, allowing customers to have more power to make a purchasing decision. The customers today are also highly informed due to all the information available over the internet. Due to the digital transformation, there are many new digital marketing channels. Retailers need to use all these channels to reach out to customers. More effort and a marketing strategy are required to holistically engage the customers through the various channels. It is also important to capture customer data from the multiple channels and effectively segregate it. The channels used by retailers are an important source of customer data. Use of omnichannel marketing helps in enhancing customer experience. The customer contact points can be used to understand what customers sense, feel, think, or behave, and ensure consistent experience. The customer data can be thus useful to understand consumer behavior at each point of transaction, and databases can be created to formulate strategies (Loureiro, 2018).

Application of analytics to the customer data can provide important insights to formulate strategies that enhance customer experience and improve engagement possibilities. Thus, the study tries to fill the research gap about using omnichannels of retailing to gather the data and use it to find the customer insights. The literature studied generally talks about how brands capture either their store information or, in case of an e-commerce website, only the online data. Retailers need to link the data captured online and in offline stores. The objective of the study is to establish how capturing and analyzing customer data can help retail companies to overcome challenges and survive longer. We realize that physical stores will become key destinations for unique sensory shopping experiences and thus omnichannel retail will improve operational productivity. The exploration inspects the data collected through online channels and shows what sort of experience customers are looking for. Second, it also provides consumer insights about the various areas of satisfaction and dissatisfaction with a retailer's service and product, and shed light on whether providing retailtainment can increase sales of a store. This section is followed by a review of past literature related to the study and the methodology section. Next is the analysis of the research and the discussion section explaining the findings of the study in detail. Lastly we have the conclusion section, which covers the limitations of the study. 


\section{LITERATURE REVIEW}

The retail scene is confronting quick transforms from an expanding portion of advanced and versatile shopping. However physical retailing, despite the disruptions, holds promise with regard to providing extraordinary customer encounters (Grewal, Levy, and Kumar, 2009; Verhoef et al., 2009). Exploration has characterized brand understanding as a shopper's arrangement of emotional, inward reactions-for example, sentiments, sensations, discernments, and practices, evoked by brand-related boosts (Brakus, Schmitt, and Zarantonello, 2009). Conversely, with brand demeanor and brand discernment, brand experience requires either the utilization of the brand or past contact with brand touch points, for example, advertisements, social media, or administrations (Brakus et al., 2009; Lemon and Verhoef, 2016). In contrast to the web stores, experiential physical stores take into consideration the providing of a haptic and increasingly extreme experience (Peck and Childers, 2003) and have knowledgeable sales work force promptly available (Gensler, Neslin, and Verhoef, 2017).

The word retailtainment is defined in terms of use of ambience, emotion, sound, and activity to get customers interested in the merchandise and in a mood to buy (Ritzer and George, 1999). To advance the day-to-day selling of merchandise into a greater occasion for shoppers, brands-notwithstanding their customary outlets-have started to set up stores intended to convey unprecedented encounters. Indeed, even advanced eyewear disruptor Warby Parker opened a lead store in New York City to make an exceptional brand understanding for its clients (Kasperkevic, 2013). An association's legacy, item development, personalized administration, and selective, future product offerings are shown as a way to encounter the brand in an uncommon manner, adding to what shoppers definitely know from conventional brand contact points (Borghini et al., 2009; Nierobisch et al., 2017). Developing writing has recognized the job of lead and spring-up stores in brand correspondences (e.g., Kozinets et al., 2002; Dolbec and Chebat, 2013; Klein et al., 2016); be that as it may, information is as yet restricted about the capability of these stores to refresh buyers' perspective of the brand from previous encounters and produce sales, especially in the non-luxury segment of retail.

We expand on retailing and buyer exploration to propose that recreational versus task-arranged inspiration influences responsiveness to experiential signs (Childers et al., 2001; Kaltcheva and Weitz, 2006) and that purchasers who visit a store unexpectedly will in general react more decidedly to instore upgrades than buyers who arranged their visit ahead of time (Bucklin and Lattin, 1991; Brüggen, Foubert, and Gremler, 2011). We contend that persuasive direction directs the degree to which a retail experience refreshes customers' image involvement with an experiential retail location. We likewise contend that brand remarkable quality is a mediator of this relationship. Brand striking nature impacts promoting viability (Miller and Berry, 1998) and inspires positive brand-related practices (Park et al., 2010). Moreover, experiential signs at a store may bring about an increasingly positive brand experience when brand remarkable quality is high. Experiential retail focuses to provide both "feel" experience, which is related to consumer's own emotions and mood (Lee et al., 2006) and "think" experience, which inflames consumer's curiosity and pleases their creative thoughts (Schmitt, 1999). It has been suggested that generating experiences does not necessarily require new tools (Holbrook and Hirschman, 1982) but better application of existing technology that intensifies the experience that the consumers gain. Among the various experiential marketing dimensions, such as situation, word of mouth, interaction, price, and experience, it seems that experience has the most impact on brand equity (Shafiee, Haghighizade, and Rahimzadeh, 2019).

Existing models of experiential retail location adequacy are static, in that they don't represent brand experience recognitions prior to the entrance of a customer in a store. On the off chance that client and brand encounters are undoubtedly of a powerful sort (Verhoef et al., 2009; Schmitt, Brakus, and Zarantonello, 2014) and update at different brand contact focuses (Lemon and Verhoef, 2016), past examination may have exaggerated the adequacy of experiential retail locations. A related weakness in surviving writing is the restricted observational proof on leader stores' capability to trigger buys, especially in non-luxury retail settings in which experiential retail locations are principally viewed as 
correspondence vehicles that improve brand recognitions (Borghini et al., 2009; Dolbec and Chebat, 2013). The challenge for retailers today is to deliver a seamless holistic experience that is consistent in every channel and technology the consumer chooses to access the brand (store, website, mobile, tablet, etc.), coined as "omnichannel" (Pratt, 2012). It is a great way for retailers who want to please those customers who seek the advantages related to both the physical and digital world (Rigby, 2011). With this foundation, it is basic to look at whether and what sort of buys are created at experiential retail locations. To provide the experience, we require the insights about the consumer and for the insights we need the retail data, customer data, to be captured. The one who masters the hidden information in the data holds more power to control the market share (Chen et al., 2015).

Data can be collected using multiple sensors in a physical retail store, which may track customers. This will help retailers to understand customer behavior and provide customized deals (Hurewitz, 2014). A drawback of creating experiential model is the difficulty of measurement. Although retailers can calculate customer turnover and satisfaction, they are unable to quantify parameters such as delight (Srinivasan and Srivastava, 2010). Research has been conducted using a comparative case design, with five retailers selected to illustrate the research objective of how the use of technology enhances the customer shopping experience within fashion retail environments (Yin, 2014). Another powerful method in the context of retail is Basket analytics, which helps to gain information and knowledge about a shopper's buying habits and preferences (Griva, 2018). Using web and text mining techniques, we can provide semantics to data that are captured in retailers' databases. The knowledge base supported by intelligent tools can help to build individual customer profiles (Ghani, 2003). Sometimes problems occur due to the unstructured nature of the large amount of data collected. Thus, to understand the sentiments hidden in the customer reviews, we need sentiment classification models (Kazmaier and van Vuuren, 2020). Thus, the one who masters the hidden information in the data holds more power to control the market share (Chen et al., 2015).

\section{Using Data Analytics to Solve Challenges and Adopt Experiential Retail}

In retail, customers shop via two types of channels. One is multichannel retailing and the other is omnichannel retailing. Multichannel retailing means retailers using more than one channel to sell their products and services. It is about exploring more than just brick and mortar or only online marketplaces. For example, most e-commerce retailers start their journey through one sales channel. They create a virtual shopping platform through a dedicated website or marketplace. Retailers have realized with time that buyers have many touchpoints and tracks to purchase. Thus, the retailers need to branch out to access these channels. In a survey about shoppers in America, it was found that 74 percent of them shopped at large retailers, 54 percent shopped from e-commerce platforms, 44 percent from webstores, and 36 percent from category-specific retailers. Organizations that can execute a good diversification strategy will succeed in both market reach and increasing sales. The issue with multichannel is that the different channels work in silos. This leads to channel clashes that have perplexed huge organizations for quite a long time. The rivalry among channels occasionally becomes more intense than with the outside world, adding considerably more to the rundown. The emphasis of omnichannel is on the interplay between channels and brands (Hsieh et al., 2012; Verhoef et al., 2015). It offers a holistic view of channels but is not confined to retail channels like physical store or online website. It includes mobile channels such as mobile devices, applications, social media, and customer touchpoints (Baxendale et al., 2015; Picot-Coupey et al., 2015; Verhoef et al., 2015). The omnichannel idea includes the combination of different channels to provide the customers a personalized experience through the channel they decide to choose. A genuine omnichannel experience would imply that one transaction can range over more than one channel. A consumer can, for instance, buy an item on the web (digital environment) and they can pick it up from the supplier's retail outlet. The purpose of this method is to provide seamless experience.

All these channels act as an important source for collecting customer data. Retailers ought to have the option to improve the consistent shopping experience by moving toward their omnichannel 
techniques from an experiential marketing point of view. They can thus concentrate on the contact points where the retailer could bring out customers' sense, feel, think, and act responses that are required to be distinguished and executed across channels, guaranteeing a progressively consistent encounter across channels. The insights could help decide the key contact areas that retailers need to use, along with customers' behavior at each point, to be able to guarantee an enhanced customer experience. Collecting and storing a large volume of historical data in companies' databases helps in formulating purchasing strategies (Loureiro, 2018).

After finding the right source for data collection, correct technology adoption has become a key factor for achieving success today. Retail industry is one of the leading industries in adopting data analytics to improve the business. An ongoing McKinsey study shows that among US retailers involved with supply chain activities, the individuals who have embraced use of data analytics in their decision making have seen up to a 19 percent expansion in working margin in the course of the last five years. The trick to make brick click is by combining conventional preferences with key elements of success of the digital experience.

The digital innovations and cheap prices of internet and memory storage have made capturing data very convenient. This has led to the boom of data analytics and thus using data to provide with invaluable insights. Data analyzing is important to be able make changes, bringing what the customer wants and thus earning their favorability. This plays a big role in generating profits. The potential of analyzing all the data generated in the retail world is huge. Some of the key areas where data analysis can be useful in retail are-price optimizing, low cost business development, performance prediction, demand and sales prediction, ROI opportunities, and identifying the target customer.

To really shine out among the large number of competitors, retailers should find a way to transport the digital world to brick and mortar shops to satisfy customers and create loyalty. Here the focus for experiential retailing is to use omnichannels as the main source for gathering information about customers. Applying analytics on it will help to increase customer reach. Retailers want to take up the problem regarding the growing gap in customers' expectation and their encounters. This can be answered by the data collected about customer's buying journey. Even if retailers end up collecting a large volume of data from multiple channels, most retailers are unaware of how to find insights on the buying patterns. Just 8 percent of retailers in a recent survey mentioned that they have a comprehensive perspective on their client base (European Retailers, 2016). It is about being able to figure out how to provide the right thing to the customer at the right time and right place.

\section{Research Methodology}

The research has been done considering one retail brand as the focus of this study. The brand chosen is the global footwear brand ALDO. It is based in Canada and is a company that has adopted use of big data. The footwear and accessories company that focused away from adopting the omnichannel thought process. It considers its customer channel agnostics. ALDO also believes that brick and mortar stores are the places where most information lies about how their customers shop. Despite all their strategies, ALDO declared itself bankrupt in May 2020. ALDO is one of the companies that had adopted selling its products through both online and offline channels. Thus, the retail shoes and accessories brand had managed to keep its customers engaged through multichannel retailing. To show the importance of data in providing buying experience, it has been collected through various market channels. In the research study, importance has been given to capturing online data about the brand, than capturing data from physical stores.

\section{Data Collection}

For the research, focus was to collect secondary data. Data has been collected in the form of customer reviews and people's say about the shoe retail brand ALDO. The two main source of data gathering are: 
1. Various online websites, digital marketplace. Websites chosen are those where reviews about the brand ALDO have been posted. An e-shopping website like Amazon is a globally popular and trusted website. Google is synonymous with being dependable for information gathering and thus was referred to for capturing review. The other websites have been chosen as per their SERP ranking on Google search engine. The websites used are:

$\begin{array}{ll}\text { - } & \text { www.sitejabber.com } \\ \circ & \text { www.influenster.com } \\ \circ & \text { www.amazon.com } \\ \circ & \text { www.trustpilot.com } \\ \circ & \text { www.mouthshut.com } \\ \circ & \text { www.reviews.io } \\ \circ & \text { Google reviews }\end{array}$

2. Tweets from Twitter-Tweets have been collected using hashtags \#aldoshoes, \#ALDO, \#AldoShoes.

The secondary data has been used to do a qualitative research. Qualitative research is used as it leads to interpretative exploration centered around scientifically uncovering certain practices or consumer behaviors. These practices or consumer behaviors are then clustered or bunched to show perceptible results.

As part of qualitative research, separate analysis methods have been used to interpret the customer reviews from Twitter and online websites respectively. Overall, the reviews have been analyzed to understand the sentiments of the shoppers purchasing shoes from ALDO.

Reviews from websites have been collected using the web scraping process. Web scraping is a method of collecting information from websites. A website's HTML page is used to scrape information. Before scraping a website, the websites were checked to ensure that terms and conditions of the site were not violated. The web scraping process was automated by writing a solution using Python programming language. Python libraries' Requests and Beautiful Soup have been used to gather the review content from website's HTML code. The extracted data were dumped into an MS excel file and used for further processing. The dataset created has 500 rows and 5 feature variables. The variables are as follows:

- Product Id: Number to uniquely identify

- Product Name: Name of product

- Reviewer Name: Person reviewing the product

- Product Rating

- Review Comment: Review comment by the purchaser of the product

Tweets from Twitter were downloaded using the Tweet Archiver, a Google API. Tweet Archiver is used to archive tweets for given hashtags and keywords, and save the data automatically in a Google sheet. A total of 16,500 tweets were collected to create the dataset.

\section{Exploratory Data Analysis}

The dataset of customer reviews from various websites has been analyzed using text mining. Text mining is the method used to change a huge amount of unstructured text to structured information for additional analyses like visualization and model structuring. Large relevant data is broken down using help of text mining algorithm and analyzed for getting actionable information for making decisions (Basha and Rajput, 2019). The text mining code is written using R programming language.

Exploratory data analysis or EDA of "Review Comment" guides us to understand how a brand impacts a customer decision. The sentiment analysis method enables us to process opinions from 
social media using text mining algorithm. The method utilizes feature extraction and selection to select words from the learning dataset and categorize them under the respective sentiment (Fiarni, Maharani, and Pratama, 2016). The analysis separates the positive and negative review to understand the difference between the two types of consumers. The first step is text attraction (Review Comment body) from the data files and tokenizing them, also called "bag of words" technique. Further pretext analyzing steps are performed and finally the term document matrix is created, which gives the frequency of the words found in the review texts. The word count is used to find the top words and represented using bar plots and word clouds. Additionally, word clustering is performed to cluster words that have been used together and are relatable.

Tweets are analyzed using Python programming. The first step is to clean the data and modify it to remove punctuations and stop words. Sentiment analysis is performed on the data to separate out the positive, negative, and neutral comments. For every comment group, the top 20 words related to the respective sentiment are extracted. These top words are plotted using bar plots and word clouds.

The review ratings that are collected are out of 5. The assumption is that review comments with rating $>3$ stars are to be considered as comments by satisfied customers and review ratings with $<$ $=3$ star are to be considered as comments by dissatisfied customers.

\section{RESULTS AND ANALYSIS}

\section{Result of the Exploratory Analysis Using Text Mining on Reviews From Various Websites}

From Figure 1 we find that some of the most common words used are shoes, comfort, fit, nice, good, perfect, love. These words are positive words. Thus, we can say that most customers have shopped shoes from the retail company. Since most of the tops words are positive, we can infer that the customers reviewing ALDO products are satisfied with their purchase.

The word cloud in Figure 2 shows the most occurring words. The frequency of the word is depicted by the size of the word in the cloud. More the frequency of the word occurring, larger the size of the word in the cloud. The colors of the cloud also give an idea about the word frequency. We see that the most occurring words are in red and the lesser occurring words are depicted in light blue. The reviews give an insight to the retailer that the customers' experience with their product has been good. Although there are happy customers, it is important to analyze the negative comments to provide improved service.

Figure 1.

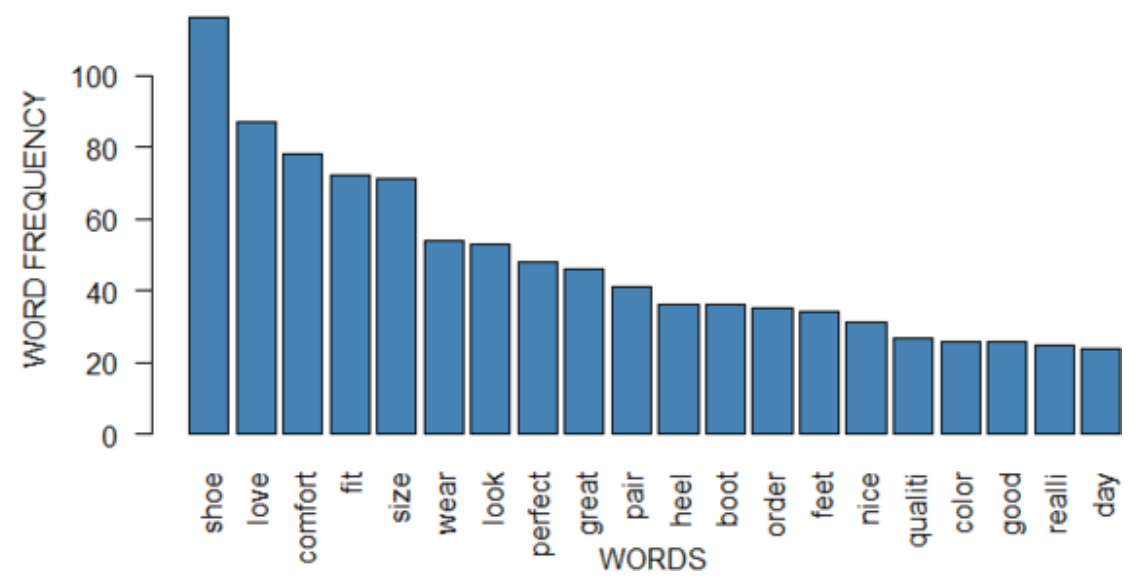


Figure 2.

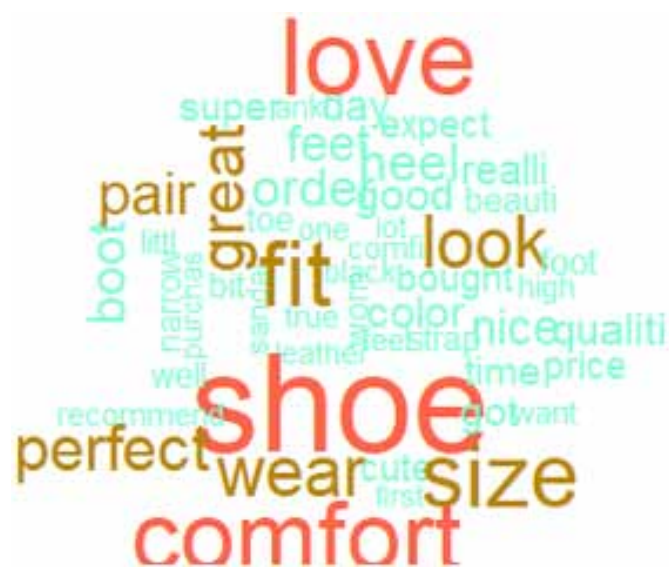

Plots in Figure 3a and Figure 3b separately show the most mentioned positive words and negative words in the customer reviews of the ALDO's product. Some of the most common words in only positive reviews are love, comfort, perfect, great, super, beautiful. From these, the retailers get an idea what customers like about their product.

Figure 3.

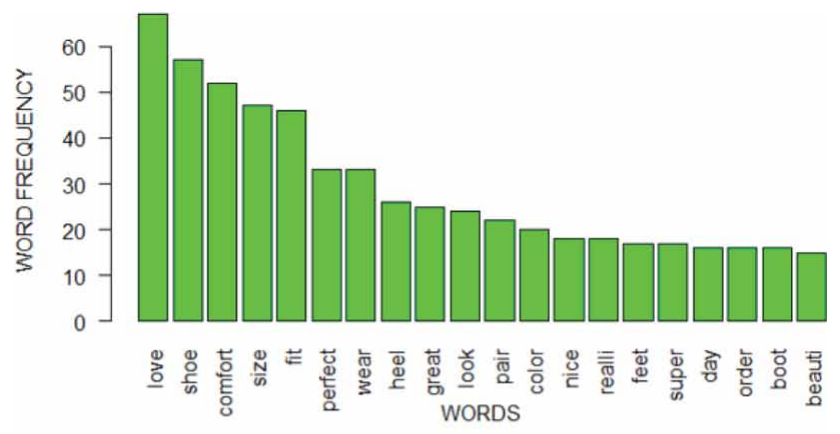

(a)

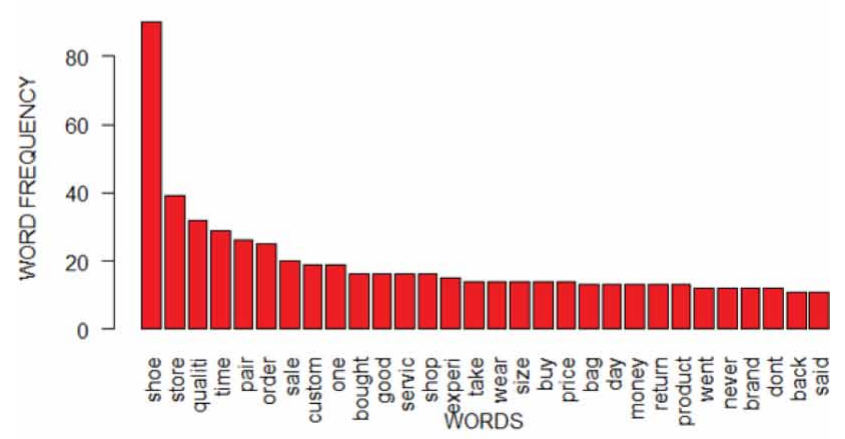

(b) 
On the other hand, the most common words in negative reviews are store, quality, service, price, money, never, don't. These words give an idea to retailers that a lot of customers who made store purchase did not have a good experience.

Figure 4 shows the top 30 words occurring in the only positive and only negative reviews. The words in green are from reviews of customers who would recommend the brand to others and the words in red are from reviews of customers who would not recommend the brand. The word cloud helps to quickly, at a glance, understand what the consumers like and dislike about ALDO's product.

A cluster dendrogram helps us to visualize which words are used together. It forms a hierarchical relationship between different words. It groups those words into related clusters. In Fig. 5 we see that words fit and perfect form one cluster, look and great form another, and comfort, wear, fit, perfect form a larger cluster. The positive words suggest that the comfort comes from perfect fit of the shoes and the pairs have great looks. The comfort and aesthetics are appreciated in customer reviews.

Figure 4.

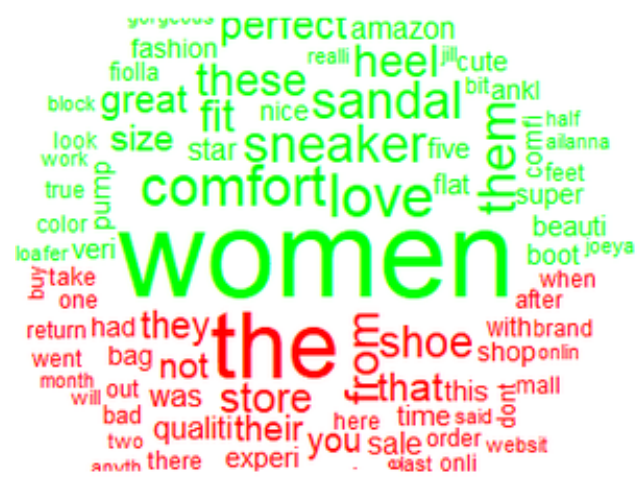

POSITIVE

NEGATIVE

Figure 5.

Cluster Dendrogram

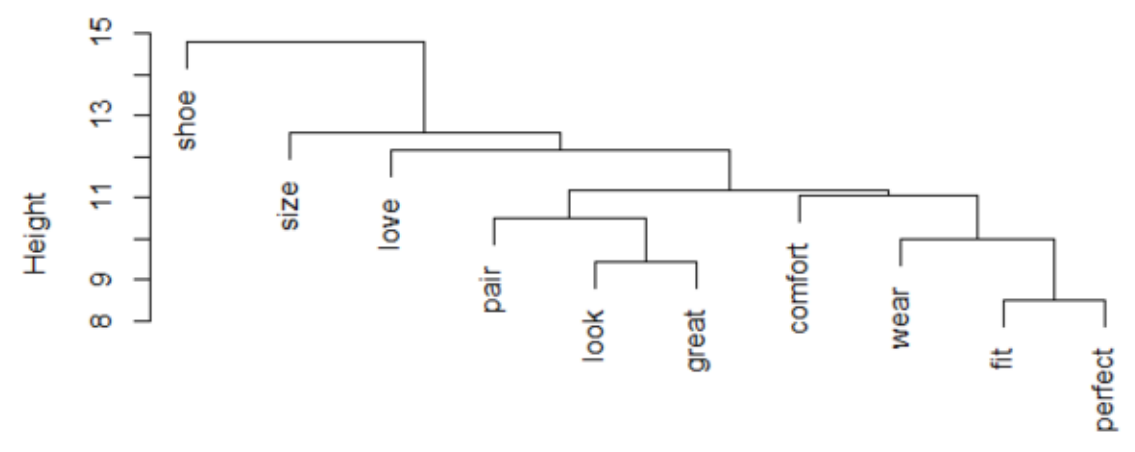




\section{Analysis of Tweets Collected From Twitter About the Brand}

Interpreting Figure 6, we understand that about two-thirds of the tweets (portion shaded in blue) collected about the brand reflect positive sentiments. Also the remaining one-third of the tweets (portion shaded in orange) reflects negative sentiment association with the brand.

In Figure 7 there are three word cloud representations. Word cloud shows the frequently occurring words in the tweets related to the brand. The first cloud represents the positive words mentioned in the tweets, the second mentions the negative words in the tweets and the third word cloud shows words that have a neutral tone to them. In the "positive text" word cloud, we see words like yes, good, wow, brilliant, love, great. The size of the word in the cloud is proportional to the frequency of its occurrence in the tweets. The "negative text" word cloud highlights words like bad, infuriating, horrible, dislike, pain. The "neutral text" cloud may be ignored or analyzed for anything unique that customers have to say about the brand.

Bar plots in Figure 8 and Figure 9 help to get an idea of how many times a particular word was mentioned in the tweet reviews. It also helps to compare the frequency among different words.

Figure 6.

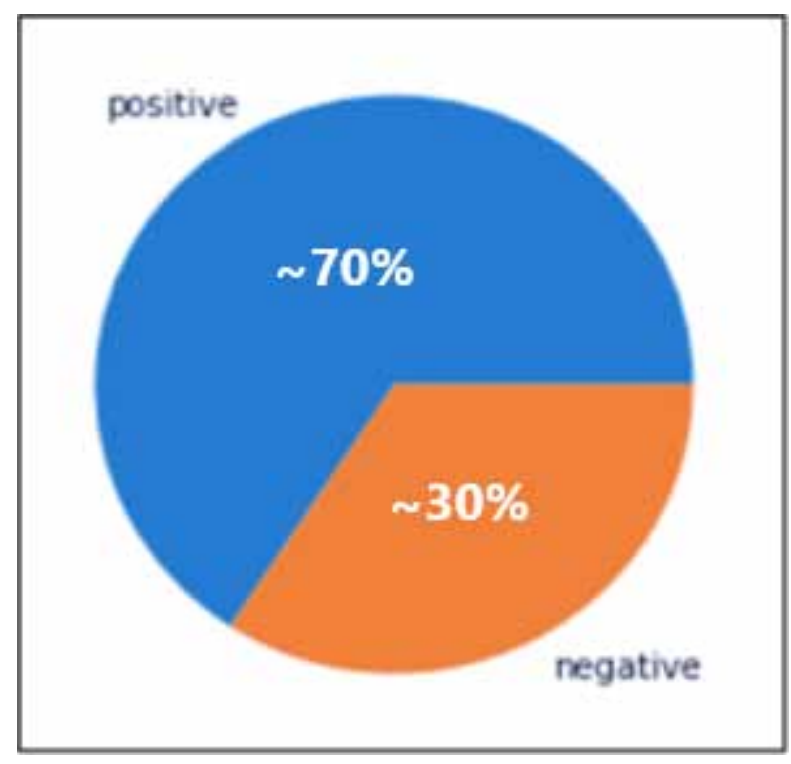

Figure 7.
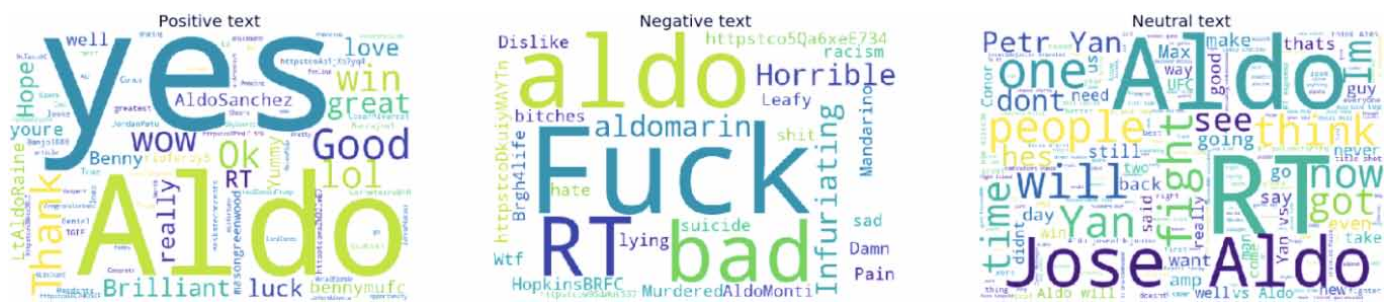
Figure 8.

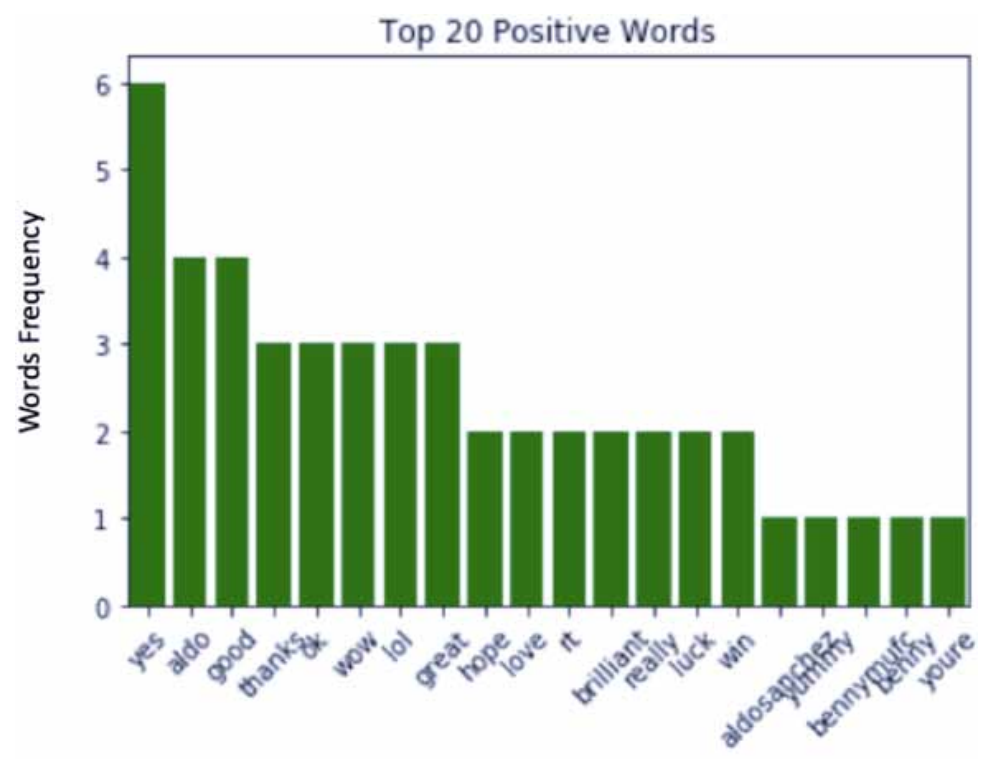

Positive Words

Figure 9.

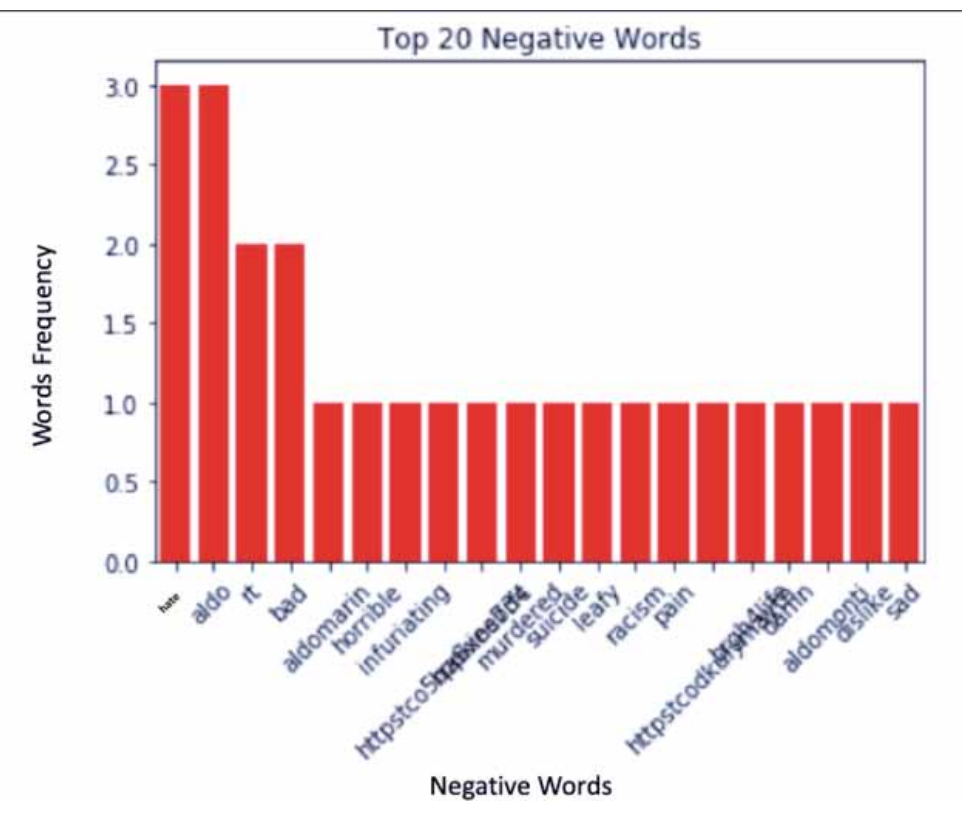

\section{DISCUSSION}

The overall analysis of the website reviews tells us that most customers are happy with their buy from the brand. This is shown through the bar plot (Figure 1) and word cloud (Figure 2) where all the top 20 words are positive words. The overall analysis of tweets also shows $\sim 67$ percent of the customers 
have given positive reviews. These analyses talk more about the satisfaction with the product and do not clearly talk about the shopping experience.

Next is comparing negative and positive reviews' bar plots. In Fig. 3a, the positive sentiments largely contain words such as "good," "super," "nice," "wow." These words are compliments for the products bought. Tweet analysis even tells us that "yes" is the topmost occurring word. From this we can conclude that those who purchased items are most probably going to recommend it to their friends and family. There are also words like "comfort," "fit," and "beautiful" that feature in the top 20. This says that consumers find brand ALDO shoes stylish and comfortable. We also find the words "heel" and "shoe" in the plot, which gives us the insight that most customers shop for shoes, and shoes with heels are the most popular products of this brand.

Analyzing the negative sentiment, plots and word clouds give insights about the brand weaknesses. It gives a better idea about the shopping experience of the customers. In Fig. 3b and Fig. 9, the most common negative words are "quality," "bad," and "dislike." This clearly tells the retailer that customers are upset about the quality of the products. Another word that features in the plots is "price" of the product, meaning the customers are not finding value for their money spent on buying shoes. Words like "store," "service," and "experience" give an important insight. There seems to be dissatisfaction with service provided, which may be customer service or store service. Words like "don't" and "never" imply that the brand created a very bad impression on the customers, and they are recommending to others not to buy. Some words that directly do not reflect negative sentiments are "time" and "sale." Since these occurred frequently in low rated reviews, retailers can infer that customers shopping during sale season are not happy with the products. On the other hand, "time" can be interpreted as problems faced by customers in receiving timely service from the retailer. A retailer should focus on solving issues mentioned in these dissatisfied customers' feedbacks. The pie chart in Figure 6 shows that almost 33 percent customers dislike the products, which is a high number. Analyzing data definitely helps retail companies to decide where their focus for improvement should be. More the data collected, more reliable are the data insights. Some of these insights narrow down the problematic areas that require further investigation.

Analyzing the dendrogram in Figure 5, word clusters depict customers who have reviewed the brand's product and found shoes to be a "perfect fit," "comfortable to wear," and they "look great." These again support the positive sentiments that we got while analyzing the tweets. The brand reviews thus speak about comfort in wearing as the fit is perfect and also that the shoes provide good aesthetics as they look great. The product reviews are thus more promising than the experiential dimensions related to the stores. The comparison of these clusters with the negative reviews provides an insight that the core functional benefits of the product like fit and look are positive while the experience of store and price are associated with negative sentiments. Dimensions that help in conceptualizing the experiential store futures model are in four forms of designed spaces: storytelling, fluid, digital zones, and community center (Alexander and Cano, 2020).

Today, to revive the brand, the reasons of dissatisfaction need to be addressed first. A study by Clemons and Gao (2008) states that no presence of strongly negative reviews can act as a significant predictor for online sales. Further studies by Chevalier and Mayzlin (2006) mention how one added negative review has a larger scale of influence in sales reduction than an added positive review has in sale increments. A study by Fiarni, Maharani, and Pratama (2016) says that using Naïve Bayes Classifier method for sentiment analysis allowed classification of the underlying opinions with 97.25 percent precision, 89.83 percent recall, and 89.21 percent accuracy. There is high frequency of words like shoes, quality, and price in the low rated comments. Retail managers need to use such insights to explore the reasons why some customers find the shoes uncomfortable to wear. Some brainstorming is also required about how to form a better pricing strategy.

The negative reviews also highlight words like store and experience. This hints to retailers that innovative ways of providing retailtainment need to be made available to their customers in their 
physical stores. Before a customer conversion, the strategy should be to attract the consumers, which will help to boost brand image. They should also invest in providing an experience through the online channels too by providing personalized recommendations and offers to their customers. In the reviews collected, we found complaints about online delivery by the brand. This clearly shows that less attention has been paid to their website. Today retailers should think about expanding with adoption of omnichannel retailing. Omnichannel will help to combine consumer data from both channels, and give one constant brand experience across all channels to consumers.

\section{CONCLUSION}

Experiential retail stores can be of different types. They can be either offline showrooms, popup stores, or flagship stores. These stores basically don't sell products; they endeavor to narrate a story. The idea behind experiential retailing is to provide an experience that will stay forever embedded in the memory of customers. This will help retailers to improve their brand image and, in turn, the brand value. The analysis of the study sheds light on the fact that retailers need to adapt to these evolving consumer preferences and understand why consumers are shopping. The analysis of customer reviews provides an understanding that for the chosen brand, productrelated functional elements like comfort and looks are able to satisfy the customers but the dissatisfaction arises from shopping experience associated with stores. Use of analytics in understanding customer reviews thus can help in improving experiential retailing. The retailers using omnichannels need to understand the importance of store experience in influencing customer satisfaction. As the reviews of users provide authentic information for potential buyers, the retailers can use customer data to generate understanding of experiential retailing. This is the way data-driven insights can help retailers to build a strong customer relationship. The intel derived by interacting with humans is invaluable. This makes brick and mortar stores so important. Today a large number of online only companies are opening offline stores. Adaption has been key to survival for retailers. During the COVID-19 pandemic crisis, we found retail brand Vero Moda using the available simple technology and apps like WhatsApp to connect to customers. They are providing improvised services like catalogue sharing, home delivery, and virtual shopping experience through video calls.

Adopting data-driven decision-making processes is an inevitable choice every retail company must make. The areas where we can use data are-for predicting customer behavior, using a recommender engine, and applying the information for pricing strategy. It can further be used for providing bots to help customers shop in stores, and these robots can capture emotions. The key is to be first and lead the way of making this adoption. This will help to arrive at remarkable degrees of personalization, accuracy, and profitability. The retailers have to reimagine and rebuild their business through the lens of sustainability. Consumers today value experiences over things. Through this paper, we can say that for enhanced shopping experience, retailers need to be creative in enabling consumers to make informed choices, enabling them to shop anywhere and anytime, providing convenience like mobile wallets and a post-purchase service.

This research is limited in scope in some areas. A shortcoming of the research is that the text mining analytics has been applied to data collected from only one brand, thus introducing bias in data collected. The data collection does not holistically cover all market channels of omni- or multiretailing. Data has been sourced only from websites and social media like Twitter. Due to COVID-19 pandemic situation across the world, we were unable to capture customer data from physical stores. In terms of measurement of experiences, there is still no proper metrics that allows us to gauge whether there is any direct effect of experiential retailing in improving a brand, and its impact on profits. 


\section{REFERENCES}

Adityan, H., Harikrishnan, K., Anand, S. J. J., \& Saju, B. (2017). Innovativeness and uniqueness as motivations for online shopping tendency and the mediating role of information acquisition. International Journal of Business Innovation and Research, 13(1), 30-51. doi:10.1504/IJBIR.2017.083264

Alexander, B., \& Cano, M. B. (2020). Store of the future: Towards a (re) invention and (re) imagination of physical store space in an omnichannel context. Journal of Retailing and Consumer Services, 55, 101913. doi:10.1016/j.jretconser.2019.101913

Basha, S. M., \& Rajput, D. S. (2019). An innovative topic-based customer complaints sentiment classification system. International Journal of Business Innovation and Research, 20(3), 375-391. doi:10.1504/ IJBIR.2019.102718

Baxendale, S., Macdonald, E. K., \& Wilson, H. N. (2015). The impact of different touchpoints on brand consideration. Journal of Retailing, 91(2), 235-253. doi:10.1016/j.jretai.2014.12.008

Begley, S., Fox, R., Lunawat, G., \& MacKenzie, I. (2018). How analytics and digital will drive next-generation retail merchandising. https://www.mckinsey.com/industries/retail/our-insights/how-analytics-and-digital-willdrive-next-generation-retail-merchandising

Borghini, S., Diamond, N., Kozinets, R. V., McGrath, M. A., Muñiz, A. M. Jr, \& Sherry, J. F. Jr. (2009). Why Are Themed Brandstores So Powerful? Retail Brand Ideology at American Girl Place. Journal of Retailing, 85(3), 363-375. doi:10.1016/j.jretai.2009.05.003

Brakus, J. J., Schmitt, B., \& Zarantonello, L. (2009). Brand Experience: What Is It? How Is It Measured? Does It Affect Loyalty? Journal of Marketing, 73(3), 52-68. doi:10.1509/jmkg.73.3.052

Brüggen, E. C., Foubert, B., \& Gremler, D. D. (2011). Extreme Makeover: Short- and Long-Term Effects of a Remodeled Servicescape. Journal of Marketing, 75(5), 71-87. doi:10.1509/jmkg.75.5.71

Bucklin, R. E., \& Lattin, J. M. (1991). A Two-State Model of Purchase Incidence and Brand Choice. Marketing Science, 10(1), 24-39. doi:10.1287/mksc.10.1.24

Chen, C. B., Agrawal, D., \& Kumara, S. (2015). Retail analytics: Market segmentation through transaction data. In IIE Annual Conference. Proceedings (p. 1034). Institute of Industrial and Systems Engineers (IISE).

Chevalier, J. A., \& Mayzlin, D. (2006). The Effect of Word of Mouth on Sales: Online Book Reviews. JMR, Journal of Marketing Research, 43(3), 345-354. doi:10.1509/jmkr.43.3.345

Childers, T. L., Carr, C. L., Peck, J., \& Carson, S. J. (2001). Hedonic and Utilitarian Motivations for Online Retail Shopping Behavior. Journal of Retailing, 77(4), 511-535. doi:10.1016/S0022-4359(01)00056-2

Clemons, E. K., \& Gao, G. (2008). Consumer informedness and diverse consumer purchasing behaviors: Traditional mass-market, trading down, and trading out into the long tail. Electronic Commerce Research and Applications, 7(1), 3-17. doi:10.1016/j.elerap.2007.10.001

Devitt, S., Ruud, A., Gober, D., Parkhill, J., Greenberger, K., Wiltamuth, M., \& Wan, P. (2013). eCommerce Disruption: A Global Theme Transforming Traditional Retail. New York: Morgan Stanley.

Dolbec, P.-Y., \& Chebat, J.-C. (2013). The Impact of a Flagship vs. a Brand Store on Brand Attitude, Brand Attachment, and Brand Equity. Journal of Retailing, 89(4), 460-466. doi:10.1016/j.jretai.2013.06.003

Euromonitor International. (2015). Millennials: Impact of their Behaviour on Global Consumer Markets. Accessed at https://www.euromonitor.com/millennials-impact-of-their-behaviour-on-global-consumer-markets/report

European Retailer. (2016). European Retail in 2016, A survey report. Accessed at https://cdn2.hubspot.net/ hubfs/2405078/cms-pdfs/fileadmin/user_upload/dyna_content/ch/documents/news_2016/geomarketing/ gfk_2016_europeanretailstudy.pdf

Fiarni, C., Maharani, H., \& Pratama, R. (2016, May). Sentiment analysis system for Indonesia online retail shop review using hierarchy Naive Bayes technique. In 2016 4th international conference on information and communication technology (ICoICT) (pp. 1-6). IEEE. doi:10.1109/ICoICT.2016.7571912 
Gensler, S., Neslin, S. A., \& Verhoef, P. C. (2017). The Showrooming Phenomenon: It's More than Just about Price. Journal of Interactive Marketing, 38(May), 29-43. doi:10.1016/j.intmar.2017.01.003

Ghani, R. (2003, September). Mining the web to add semantics to retail data mining. In European Web Mining Forum (pp. 43-56). Springer.

Grewal, D., Levy, M., \& Kumar, V. (2009). Customer Experience Management in Retailing: An Organizing Framework. Journal of Retailing, 85(1), 1-14. doi:10.1016/j.jretai.2009.01.001

Grieder, P., Buck, R., Banfi, F., Kment, V., \& Fitzner, J. (2014). The future of retail: How to make your bricks click. https://www.mckinsey.com/business-functions/marketing-and-sales/our-insights/the-future-of-retail-howto-make-your-bricks-click

Griva, A., Bardaki, C., Pramatari, K., \& Papakiriakopoulos, D. (2018). Retail business analytics: Customer visit segmentation using market basket data. Expert Systems with Applications, 100, 1-16. doi:10.1016/j. eswa.2018.01.029

Hsieh, Y.-C., Roan, J., Pant, A., Hsieh, J.-K., Chen, W.-Y., Lee, M., \& Chiu, H.-C. (2012). All for one but does one strategy work for all? Building consumer loyalty in multichannel distribution. Managing Service Quality, 22(3), 310-335. doi:10.1108/09604521211231003

Hurewitz, M. (2014). U.S. Patent Application No. 13/961,140. US Patent Office.

Kaltcheva, V. D., \& Weitz, B. A. (2006). When Should a Retailer Create an Exciting Store Environment? Journal of Marketing, 70(1), 107-118. doi:10.1509/jmkg.70.1.107.qxd

Kasperkevic, J. (2013). Why Warby Parker Opened a Retail Store. Inc. https://www.inc.com/jana-kasperkevic/ warby-parker-co-founder-why-we-opened-a-flagship-store.html

Kazmaier, J., \& van Vuuren, J. H. (2020). Sentiment analysis of unstructured customer feedback for a retail bank. ORiON, 36(1), 35-71. doi:10.5784/36-1-668

Klein, J. F., Falk, T., Esch, F.-R., \& Gloukhovtsev, A. (2016). Linking Pop-Up Brand Stores to Brand Experience and Word of Mouth: The Case of Luxury Retail. Journal of Business Research, 69(12), 5761-5767. doi:10.1016/j. jbusres.2016.04.172

Kozinets, R. V., Sherry, J. F. Jr, DeBerry-Spence, B., Duhachek, A., Nuttavuthisit, K., \& Storm, D. (2002). Themed Flagship Brand Stores in the New Millennium: Theory, Practice, Prospects. Journal of Retailing, 78(1), 17-29. doi:10.1016/S0022-4359(01)00063-X

Lee, S.-H., Chang, S.-C., Hou, J. S., \& Lin, C.-H. (2006). Night market experience and image. International Journal of Culture, Tourism and Hospitality Research, 2(3), 217-233. doi:10.1108/17506180810891591

Lemon, K. N., \& Verhoef, P. C. (2016). Understanding Customer Experience Throughout the Customer Journey. Journal of Marketing, 80(6), 69-96. doi:10.1509/jm.15.0420

Loureiro, A. L., Miguéis, V. L., \& da Silva, L. F. (2018). Exploring the use of deep neural networks for sales forecasting in fashion retail. Decision Support Systems, 114, 81-93. doi:10.1016/j.dss.2018.08.010

Miller, S., \& Berry, L. (1998). Brand Salience versus Brand Image: Two Theories of Advertising Effectiveness. Journal of Advertising Research, 38(5), 77-82.

Nierobisch, T., Toporowski, W., Dannewald, T., \& Jahn, S. (2017). Flagship Stores for FMCG National Brands: Do They Improve Brand Cognitions and Create Favorable Consumer Reactions? Journal of Retailing and Consumer Services, 34(1), 117-137. doi:10.1016/j.jretconser.2016.09.014

Park, C. W., MacInnis, D. J., Priester, J., Eisingerich, A. B., \& Iacobucci, D. (2010). Brand Attachment and Brand Attitude Strength: Conceptual and Empirical Differentiation of Two Critical Brand Equity Drivers. Journal of Marketing, 74(4), 1-17. doi:10.1509/jmkg.74.6.1

Peck, J., \& Childers, T. L. (2003). To Have and to Hold: The Influence of Haptic Information on Product Judgments. Journal of Marketing, 67(2), 35-48. doi:10.1509/jmkg.67.2.35.18612 
Picot-Coupey, K., Huré, E., \& Piveteau, L. (2015). Channel design to enrich customers' shopping experiences: Synchronizing clicks with bricks in an omni-channel perspective- the Direct Optic case. International Journal of Retail \& Distribution Management, 44(3), 336-368. doi:10.1108/IJRDM-04-2015-0056

Pozzi, A. (2013). The effect of Internet distribution on brick-and-mortar sales. The RAND Journal of Economics, 44(3), 569-583. doi:10.1111/1756-2171.12031

Ritzer, G. (1999). Enchanting a Disenchanted World: Revolutionizing the Means of Consumption. Academic Press.

Schmitt, B., Brakus, J. J., \& Zarantonello, L. (2014). The Current State and Future of Brand Experience. Journal of Brand Management, 21(9), 727-733. doi:10.1057/bm.2014.34

Schmitt, B. H. (1999). Experiential marketing. Journal of Marketing, 15(1), 53-54.

Shafiee, M. M., Haghighizade, R., \& Rahimzadeh, S. (2019). The effect of experiential marketing on brand equity: study of a home appliances manufacturing group. International Journal of Business Innovation and Research, 20(2), 233-252.

Srinivasan, S. R., \& Srivastava, R. K. (2010). Creating the futuristic retail experience through experiential marketing: Is it possible? An exploratory study. Journal of Retail \& Leisure Property, 9(3), 193-199. doi:10.1057/ rlp.2010.12

Verhoef, P. C., Kannan, P. K., \& Inman, J. J. (2015). From multi-channel retailing to omnichannel retailing: Introduction to the special issue on multi-channel retailing. Journal of Retailing, 91(2), 174-181. doi:10.1016/j. jretai.2015.02.005

Verhoef, P. C., Lemon, K. N., Parasuraman, A., Roggeveen, A., Tsiros, M., \& Schlesinger, L. A. (2009). Customer Experience Creation: Determinants, Dynamics and Management Strategies. Journal of Retailing, 85(1), 31-41. doi:10.1016/j.jretai.2008.11.001

Wallace, T. (n.d.). Omni-Channel Retail Report: Generational Consumer Shopping Behavior Comes Into Focus + Its Importance in Ecommerce. https://www.bigcommerce.com/blog/omni-channel-retail/\#why-us-consumersshop-where-they-shop

White, R. (2010). Retail-tainment; the next big thing for retail and shopping centers. White Hutchinson Leisure \& Learning Group.

Manoj Hudnurkar is a Professor in operations and IT at Symbiosis Center for Management and Human Resource Development (SCMHRD), Symbiosis International University, Pune, India. Previously, he worked in Industry as Project Manager and has handled various projects. Manoj has published various papers in international journals of repute on collaborative supply chain management, supplier classification and supplier performance management. $\mathrm{He}$ also has experience in consulting projects and corporate trainings. 